\title{
Targeted Confocal Laser Endomicroscopy (CLE) for the Assessment of Putative Cancer Stem Cell Markers in Colorectal cancer - A Pilot Study
}

\author{
Irina Florina Cherciu ${ }^{1}$, Elena Tatiana Ivan ${ }^{1}$, Daniela Elena Burtea ${ }^{1}$, Mihaela Calita ${ }^{1}$, Daniel Pirici ${ }^{2,3}$, \\ Claudiu Margaritescu ${ }^{2,3}$, Adrian Săftoiu ${ }^{1,4}$
}

\author{
${ }^{1}$ Research Center of Gastroenterology and Hepatology Craiova \\ University of Medicine and Pharmacy of Craiova, Romania \\ 2Department of Pathology, University of Medicine and Pharmacy of Craiova, Romania \\ ${ }^{3}$ Department of Research Methodology, University of Medicine and Pharmacy of Craiova, Romania \\ ${ }^{4}$ Gastro Unit, Division of Endoscopy, Copenhagen University Hospital Herlev, Denmark
}

\section{ABSTRACT}

Background: Colorectal cancer is one of the most common diagnosed malignancies in the world. Successful treatment is related not only to the resection of the main tumor mass but also to the destruction of colorectal cancer cells which are highly resistant to chemoradiotherapy, with unlimited self-renewal and tumor-initiating capacities. CD44 is an important adhesion molecule and one of the proposed stem cell markers in colorectal cancer known to be involved in cell growth, differentiation and survival.

Aim: We conducted a prospective study with the aim of evaluating the feasibility of confocal laser endomicroscopy (CLE) to identify and assess the distribution patterns of CD44, taking into consideration further directions related to the role that CD44 might play in improving tumor assessment, individualized cancer therapy and better tumor control.

Methods: Fresh biopsies from tumor and normal tissue were collected from 13 patients previously diagnosed with primary colorectal adenocarcinoma during routine colonoscopy procedures, with pathology confirmation. A series of optical slices were immediately collected after staining each sample with fluorescent anti-CD44 antibodies, using a dedicated CLE system and analyzed using Image $\mathrm{J}$. The images with the most pronounced fluorescent signal and a clear display of the tissue and stem cells were selected.

Results: Our study included 13 patients, with an average age of $60 \pm 14,2$ years. A number of 537 slides were analyzed, stacked and the most relevant were selected for cell counting. Standard biopsy sections from normal mucosa showed a well defined layout of the mucosal structures while this characteristic was lost among the tumor samples. CLE evaluation of the selected images revealed $34,92 \pm 16$ cells/slide for the tumor tissue and $22,77 \pm 11,65$ cells/slide for the normal tissue $(p=0,037)$.

Conclusion(s): Targeted CLE based on fluorescent anti-CD44 antibodies was found to be feasible for real-time imaging and evaluation of CD44 positive cells in CRC patients, although further extended studies are required.

Core TIP: An increasing amount of data regarding the immunohistochemical or genetic assessment of putative cancer stem cell in colorectal cancer is available, stating their importance in tumor development, metastasis or tumor relapse. In our study we evaluated one of the main cancer stem cell biomarkers that literature is proposing, CD44. To our knowledge, this is the first time when a state-of-the-art technique such as confocal laser endomicroscopy was used to describe the expression patterns of CD44 in fresh human
Corresponding author: Adrian Săftoiu, MD, PhD, MSc, FASGE Visiting Clinical Professor Gastrointestinal Unit, Copenhagen University Hospital Herlev, Denmark Professor of Diagnostic and Therapeutic Techniques in Gastroenterology Research Center of Gastroenterology and Hepatology of Craiova, Romania University of Medicine and Pharmacy Craiova, Romania 2 Petru Rares str., Craiova, Dolj 200349, ROMANIA Fax: +40 0251310287

E-mail: adrian.saftoiu@umfcv.ro or adriansaftoiu@aim.com 
colorectal cancer specimens. Our results suggest that targeted CLE is feasible for real-time imaging and evaluation of CD44 positive cells in CRC patients.

Key words: confocal laser endomicroscopy (CLE), biomarkers, CD44, putative cancer stem cells, colorectal cancer

\section{INTRODUCTION}

Colorectal cancer (CRC) is the third most frequently diagnosed cancer worldwide, recording approximately 1.4 million new cases in 2012 (1). The number of newly diagnosed cases is expected to increase in parallel with the aging of the population, a phenomenon which is already occurring in all developed countries $(2,3)$. Although an improvement of relative survival is observed in western countries, the problem of treatment failures and tumor recurrence remains a keystone. Multiple therapeutic protocols have been dedicated to CRC and several research studies have determined conventional prognostic factors, without yielding a complete cure in all cases (4).

Recently, the proposed identification of colon cancer stem cells (CSCS) has received a major attention due to their potential in improving cancer treatment. The hypothesis considers that chemoresistant cells are molecularly and phenotypically distinctive, overexpressing markers of CSC (5), while on the other side CSCs display characteristics of cells which shows resistance to standard chemotherapy treatment, hence its importance (6). Only few studies target the alterations of CSCs after treatment. In a pilot study including 99 patients with rectal cancer, tumor regression was observed after preoperative radio- and chemotherapy. Biopsy and tumor specimens were compared regarding the fractions of CD133 positive cells, showing that patients presenting an increased number of CD133 positive cells which was associated with high rate of distance recurrence, worse disease free survival and overall survival (7).

Opposite to the conventional stochastic model (stating that any cell has an equivalent potential of cancer initiation and promotion), the newly concept of cancer stem cells (CSCs) brings additional data stating that intratumoral heterogeneity can result from a functional diversity among cells in various states of differentiation. Accordingly, the tumors are organized in a definite hierarchical degree and only CSCs are the cancer progenitors, requiring the accumulation of genetic/epigenetic alterations and acquiring subsequently the potential of tumor initiation, growth and therapy resistance (8). Regarding the identification of CSCs, the gold standard assay is represented by serial transplantation in animal models, a laborious and time consuming method. Isolation of CSCs from colorectal cancer can be accomplished through hematopoietic or embryonic stem cell development methods by selecting a subpopulation cells based on the expression of one or multiple cell surface markers. Hence, reliable markers that identify CSCs will enhance the understanding signaling pathways and other regulatory mechanisms. Proposed specific antibodies directed at the protein markers present on the cell surface include CD44, CD133, CD166, beta1 integrin-CD29, CD24, Lgr5, EpCAM (ESA), Msi-1, EphB, DCAMLK1 or ALDH-1 receptors (8). CD44 is a transmembrane glycoprotein, a unique adhesion molecule, being proposed as one of the main colorectal CSCs markers, considering its involvement in several cellular processes as cell growth, motility, tumor differentiation and patient prognosis (9).

Immunohistochemical staining, direct stem cell labeling with flow cytometry and fluorescence microscopy, as well as reporter-gene imaging, represent some of the means used for visualizing CSC. Overall, optical, nuclear, and magnetic resonance imaging are current methods of identifying and investigating the sophisticated mechanisms behind CSC behavior. Among the optical options for cell visualization, confocal laser endomicroscopy (CLE) is an innovative endoscopic imaging method enabling real time histological examination of the gastrointestinal tract mucosa. Not only that it provides "optical" biopsies but is also offers to the endoscopist the opportunity of prompt interpretation and intervention. It has high sensitivity and specificity, being proposed as an alternative endoscopic method to differentiate neoplastic from non-neoplastic lesions (10).

With an accuracy of $99.2 \%$, CLE can predict the neoplastic character of a lesion based on the altered cells and blood vessels architecture thus enabling virtual histology of living cells $(11,12)$. Immunoendoscopy, the association of CLE with targeted biomarkers (fluorescently labeled antibodies and peptides which directly bind to their targets) has been proven to be feasible with the possibility of being translated into clinical practice. It has the potential to distinguish and characterize the molecular changes appearing in neoplasia, thus the possible role to be played for diagnosis and therapeutic innovations (13).

\section{Aim \\ We conducted a prospective study with the aim of evaluating the distribution patterns of CD44 positive}


cells by CLE, considering the role that it might play in colorectal cancer assessment, prognosis evaluation, as well as personalized cancer therapy and enhanced tumor control. Taking into consideration the rising evidence regarding the critical role that CSCs play in both tumor initiation and drug resistance, but also in relapse following chemotherapy, we examined the putative CSC expression in tumor tissue as well as in normal colonic mucosa.

\section{MATERIAL AND METHODS}

\section{Patients and specimens}

This prospective pilot study was based on a series of 13 patients, diagnosed with different stages of colorectal adenocarcinoma during routine colonoscopy procedures and confirmed by conventional pathology assessment. CRC staging was determined based on the association of radial endoscopic ultrasound (EUS) and computer tomography (CT). At least four fresh biopsies from tumor and normal mucosa were collected during pretreatment colonoscopy evaluation. The normal samples were collected circumferentially from approximately $10 \mathrm{~cm}$ away from the tumor margins.

\section{CLE immunostaining protocol}

Two paired samples of fresh human biopsies with an approximate diameter of $3 \mathrm{~mm}$ were harvested during colonoscopy from normal mucosa and tumor tissue of each patient and immersed in Phosfate Buffered Saline (PBS) solution 0.1 M. ph 7.2. The fresh biopsies were incubated in the dark with a mouse monoclonal antibody to MEM-85, 1:25 dilution, directed against human CD44/PGP-1 (Exbio, Prague, Czech Republic) labeled with Alexa-Fluor 488 , for 1 hour at $37^{\circ} \mathrm{C}$. This antibody recognizes both cell surface-expressed and soluble form of human CD44 as an antigen (Phagocyte glycoprotein 1). In order to optimize the staining technique, various antibody dilutions were formerly investigated on fresh specimens and viewed with a motorised fluorescence microscope (Nikon 90i, Tokyo, Japan) equipped with dedicated narrow band filter sets (Chroma Technology Corp., Bellows Falls, VT, USA), a high-quantum efficiency monochrome Rolera-XR cooled CCD camera (QImaging, Surrey, British Columbia, Canada), and the Image ProPlus AMS analysis and control software (Media Cybernetics, Bethesda, MD, USA). The optimum time framework was settled at 60 minutes, permitting the proper bind of the antibody to its target and an appropriate imaging of the samples, without tissue degradation. Before CLE imaging, the antibody solution was decanted and afterwards the samples were cleansed three times for 1-2 minutes with ice cold PBS in order to discard any unbound antibody molecules (fig. 1).

\section{CLE imaging}

In this study, we used the EC-3870 CIFK, Pentax, Tokyo, Japan CLE system whose components are based on the integration of a scaled-down confocal laser microscope mounted in the tip of a conventional colonoscope, enabling confocal microscopy in addition to standard colonoscopy (fig. $2 a$ ). The confocal lens is
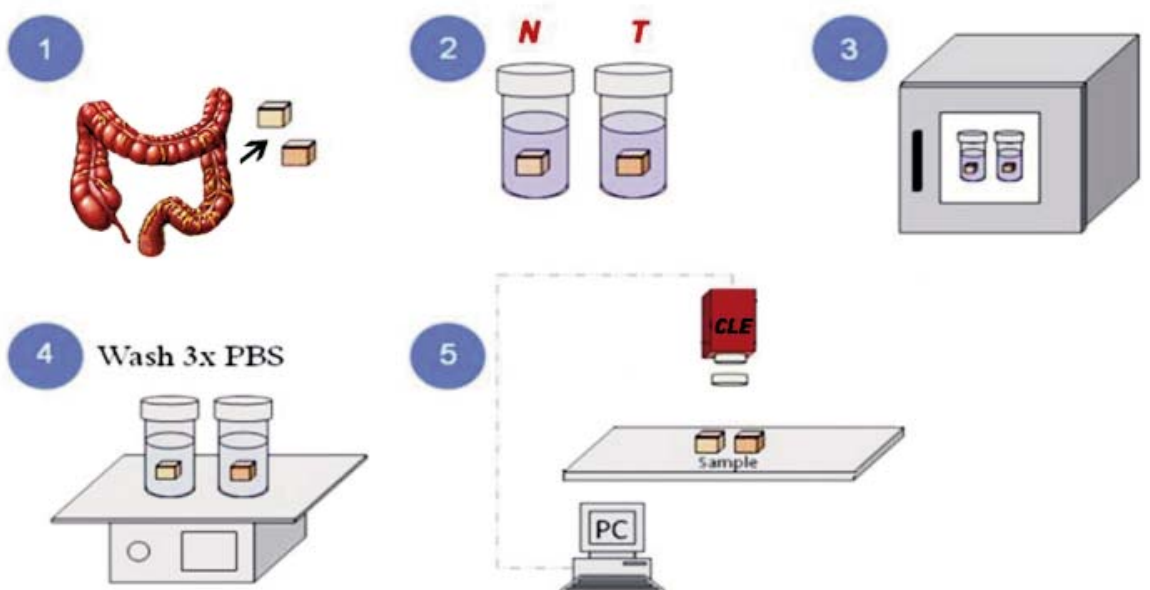

Figure 1 - CLE immunostaining and imaging protocol for fresh colorectal biopsies [modified after (13)] 


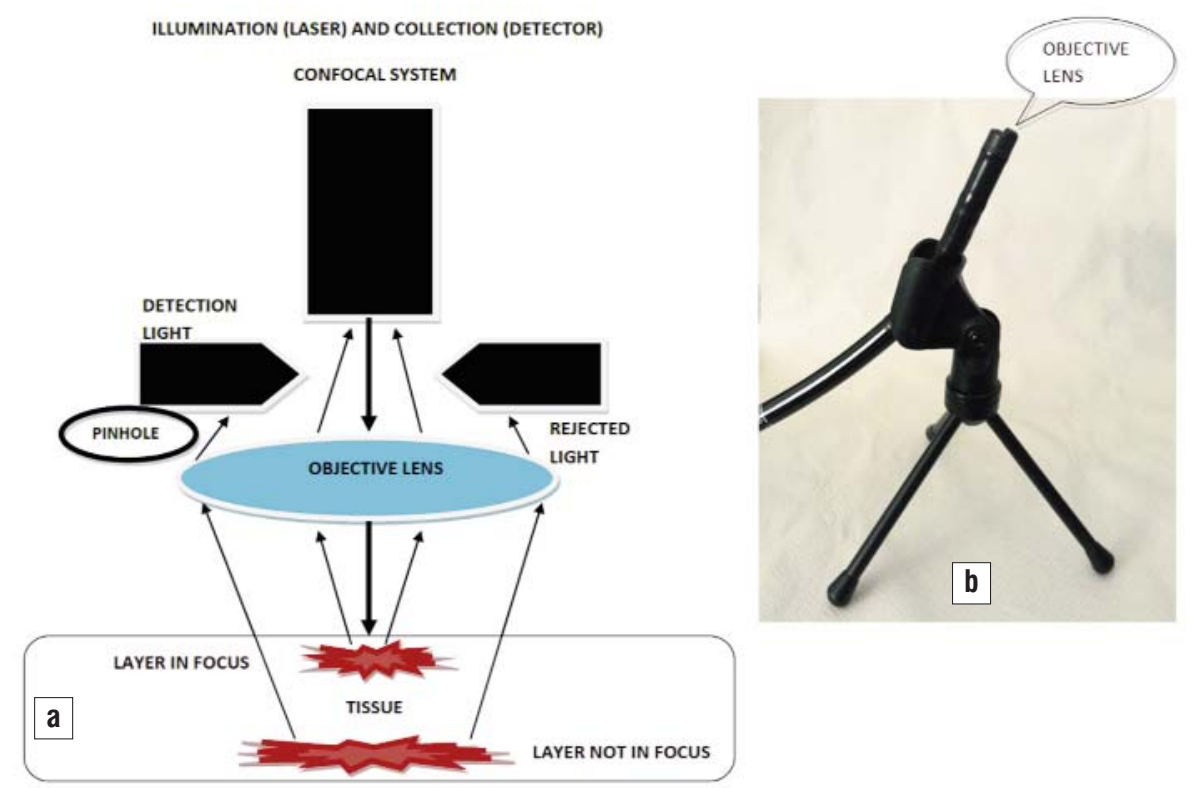

Figure 2 - (a)- CLE optical system diagram [modified after (13)] (b) - The endomicroscope had a fixed position on a tripod. Objective lens was outpointed and in direct contact with the tissue during the scanning.

positioned slightly forward, outside the distal tip of the endoscope, allowing targeted scanning of the mucosal structures. The CLE scope was firmly fastened onto a steady device, whilst the samples were placed in direct contact with the tip of the scope and gently maneuvered by the endoscopist with a small forceps for assessing the entire tissue, by shifting it on all its sides (fig. 2b). The tissue was controlled by the user during the examination for optimal imaging acquisition. The images were obtained by pressing the foot switch pedal and were digitally stored on the system's hard disk drive as standard grey-scale images (150-300 for each biopsy sample) for download and processing. During the investigation, the argon ion laser discharges an excitation wavelength of $488 \mathrm{~nm}$ with a maximum laser power output of $\leq 1 \mathrm{~mW}$ at the tissue surface. The maximum depth of imaging is $250 \mu \mathrm{m}$ from the surface of the mucosa. The resulting optical sections have a lateral resolution of $0.7 \mu \mathrm{m}$ for a $7 \mu \mathrm{m}$ thick slice and a field of view of $475 \times 475 \mu \mathrm{m}$.

\section{CSC imaging and counting method}

We analyzed the CLE images by using Image J software (National Institutes of Health, Bethesda, Maryland, USA). At least five images presenting the most intense fluorescent signal and a clear display of CD44 positive cells or tissue architecture were selected to be analyzed for the expression patterns of the studied marker. In order to enhance the intensity of the fluorescent contrast agent, a color overlay was superimposed, obtaining in the end a satisfying distinction of CD44 positive cells (fig. $3 a, b$ ). The cell count tool from ImageJ was utilized to manually mark and immediate count the number of cells located in the intestinal stroma. The results were automatically registered, exported in Excel files and recorded as the mean \pm standard deviation for the selected images in each case.

\section{Statistical analysis}

Statistical analysis was performed using Microsoft Office Excel $^{\circledR}$ and the results were expressed as averages \pm standard deviation (SD) of the mean. The two-tailed Student or paired $t$ test was used to determine the significance of the differences between the cancer stem cells count in the paired biopsies. All analyses were performed at a significance of $5 \%$ ( $p \leq$ $0.05)$. Pearson's correlation coefficient $(R)$ calculation was used to evaluate the linear rapport between pairs of quantitative variables.

\section{RESULTS}

A total number of 13 patients were prospectively enrolled. The overall ratio female: male ratio was 1: 4,1 with an average age of 59,84 $\pm 14,5$. Overall, 11 cases were diagnosed with rectal cancer and 2 cases with 


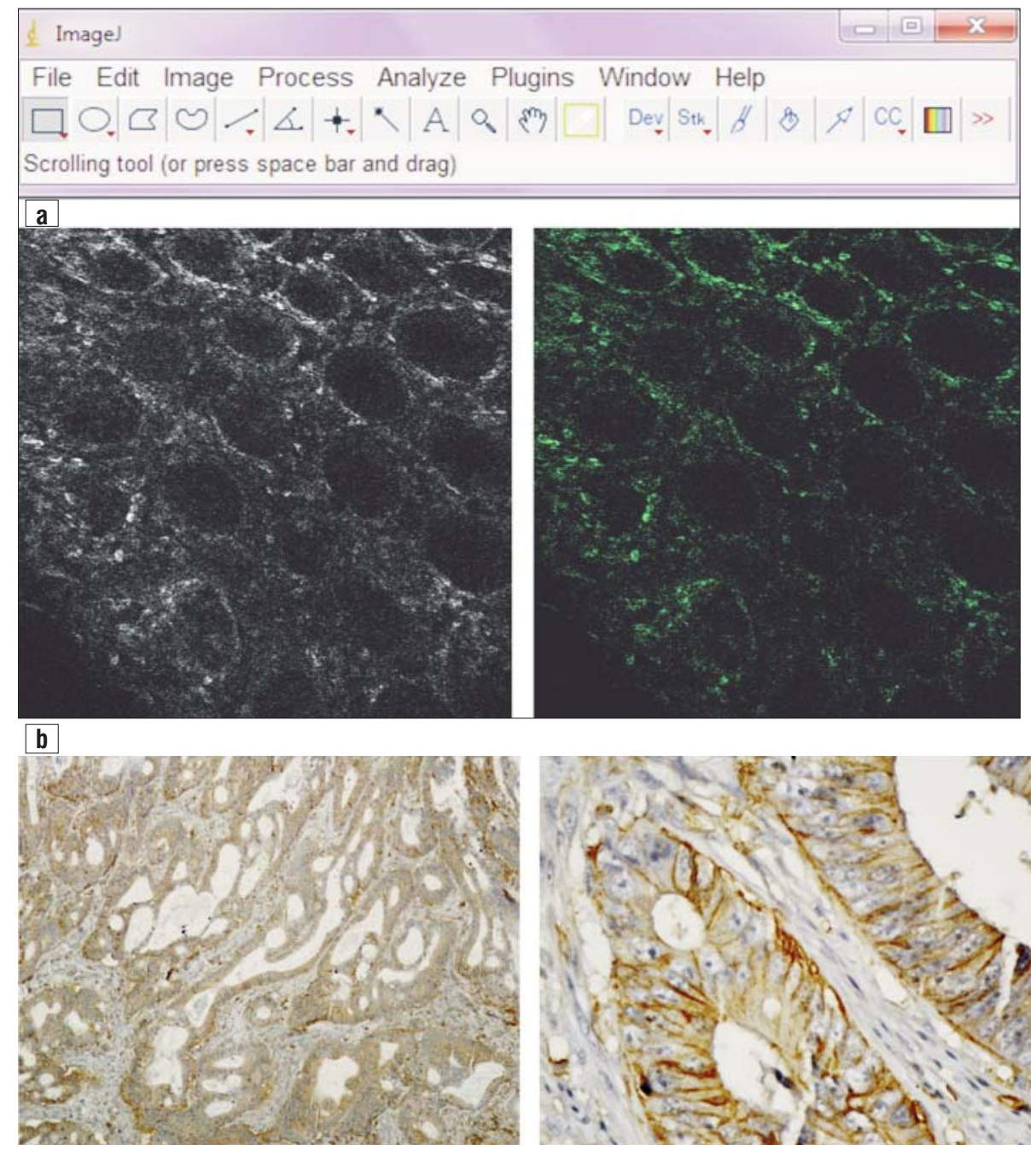

Figure 3 - (a) - Confocal laser endomicroscopy image of control colon tissue marked with fluorescently labeled anti-CD44 antibody (originally visualized as grey scale by the camera, and pseudo colored in green in ImageJ); (b) - Pathological confirmation of the staining pattern at the tissue level in a moderately differentiate CRC. A diagnostic-grade anti-CD44 antibody elicits on the same biopsy specimen a membranous stining pattern that is present in both tumor epithelial cells, but also in stromal cells.

sigmoid cancer. Five cases were well differentiated (G1), 6 cases were moderately differentiated (G2), and 2 cases were undifferentiated (G3). Taking into account the EUS tumor extension 1 case was staged as Tis, 2 cases were staged as T1, 3 as T2, 7 as T3/T4, while the description of the regional lymph nodes revealed 7 cases staged as N0; 5 cases as N1 and 1 cases as N2 (table 1).

\section{CLE patterns of CD44 positive cells}

A number of 537 image captures were analyzed, stacked and the most appropriate 65 were selected for cell counting using Image J. The distinct fluorescent signal was analyzed with the CLE scope in all biopsies, both in normal and in tumor tissue samples. Standard biopsy sections from normal tissue revealed a well defined layout of the mucosal structures, with normal size and regular arrangement of crypts and a reduced number of CD44 positive cells (fig. 4). These characteristics were lost in tumor samples, the architecture had an irregular arrangement with destroyed crypts and unrecognizable structures, while the presence of CD44 positive cells was increased (fig. 5). The signal was mostly membranar, both in the epithelial cells of the tumor arrangements, but also in the adjacent stroma, a pattern common to that observed by classical immunohistochemistry on tissue fragments further processed by paraffin embedding and staining (fig. $3 B$ ).

CLE evaluation of the selected images revealed 
Table 1 - The assessed parameters in the study group considering the age, tumor location, TN staging and tumor grading

\begin{tabular}{|c|c|}
\hline \multicolumn{2}{|l|}{ Parameters } \\
\hline No. of patients & 13 \\
\hline Age (years) & $59,84 \pm 14,5$ \\
\hline \multicolumn{2}{|l|}{ Tumor location } \\
\hline Rectum & 11 \\
\hline Sigmoid & 2 \\
\hline \multicolumn{2}{|l|}{ Staging } \\
\hline Tis & 1 \\
\hline $\mathrm{T} 1$ & 2 \\
\hline $\mathrm{T} 2$ & 3 \\
\hline $\mathrm{T} 3$ & 6 \\
\hline T4 & 1 \\
\hline NO & 7 \\
\hline $\mathrm{N} 1$ & 5 \\
\hline $\mathrm{N} 2$ & 1 \\
\hline \multicolumn{2}{|l|}{ Tumor grading } \\
\hline $\mathrm{G} 1$ & 5 \\
\hline $\mathrm{G} 2$ & 6 \\
\hline G3 & 2 \\
\hline
\end{tabular}

$34,92 \pm 16$ CD44 positive cells/slide for the tumor tissue and $22,77 \pm 11,65 \mathrm{CD} 44$ positive cells/slide for the normal tissue $(p=0,037)$. Regarding the correlation between CLE cell count and tumor $\mathrm{T}$ or $\mathrm{N}$ staging, the highest number of patients was found in T3, N0 or N1 stage category. CD44 expression was higher in tumor versus normal tissue and statistical relevant in stage T3/4: $p=0,028, r=0,622$, whilst non-significant for NO: $p=0,1, r=0,92$ and for $N 1: p=0,1, r=0,8$. The average CD44 positive cell count in tumor tissue, according to tumor grading, was as it follows: for $\mathrm{G} 1$ grade $42,8 \pm 18,8$ cells/slide, for G2 $34,7 \pm 13$ cells/slide and for G3 $19 \pm 9,89$ cells/slide. The differences regarding tumor grading were not statistical relevant.

\section{DISCUSSION}

Guidelines for the surveillance of colorectal cancer after curative treatment have been clearly established
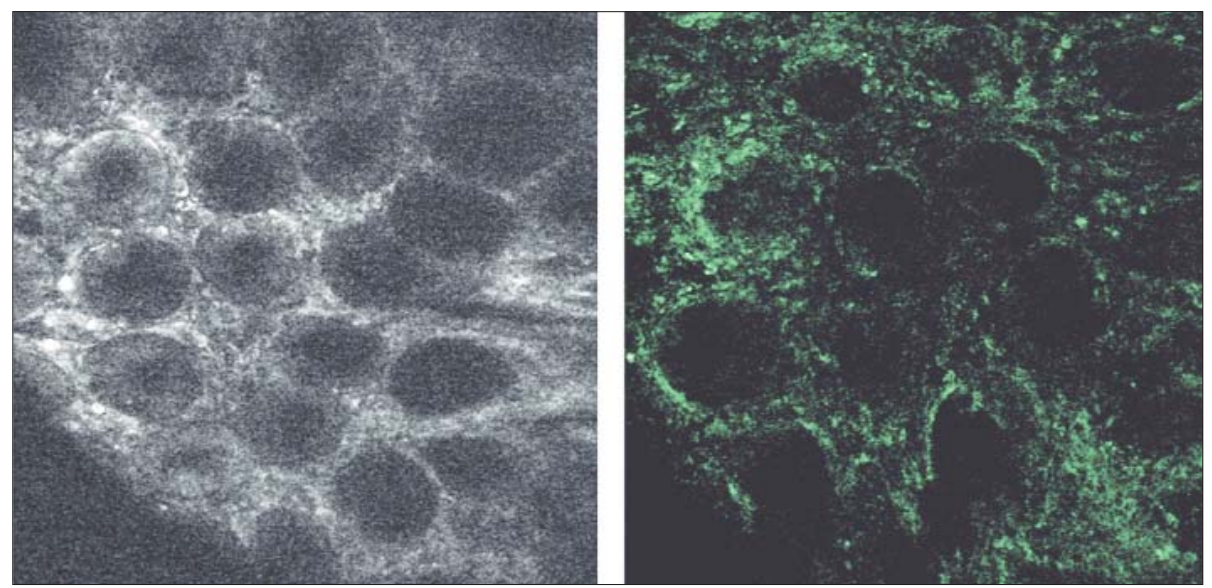

Figure 4 - Confocal laser endomicroscopy image of normal mucosa visualized with fluorescently labeled anti- CD44 antibody (ordered architecture of the mucosal structures and several round/oval shape putative CSC with a clear membrane staining pattern)
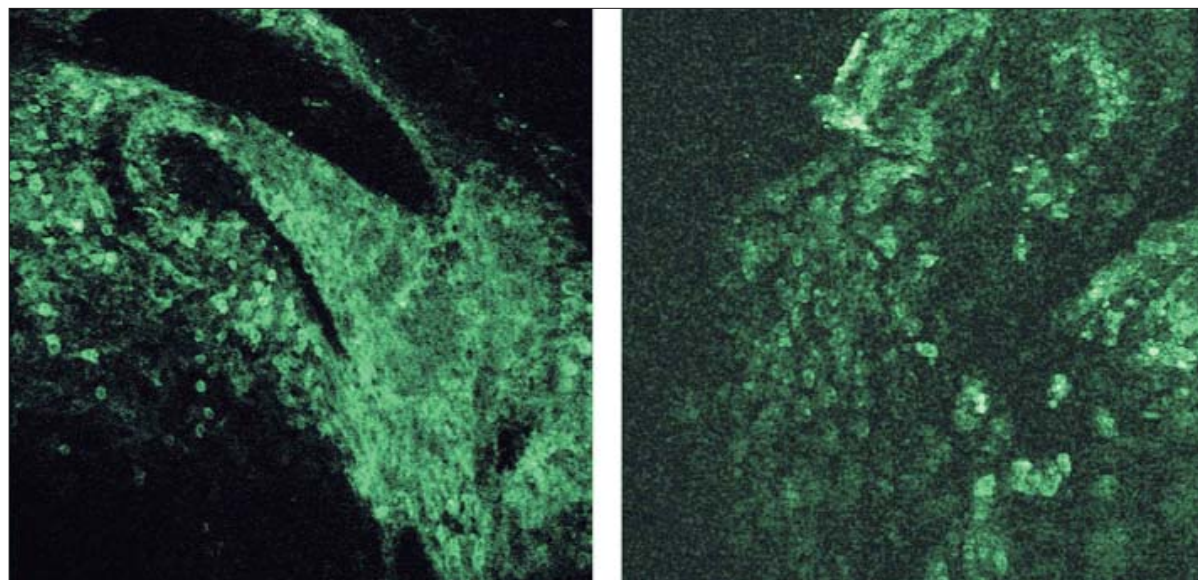

Figure 5 - Confocal laser endomicroscopy image of tumour mucosa visualised with fluorescently labeled anti- CD44 antibody (several round/oval shape CSC with a clear membrane staining pattern) 
by gastroenterology, surgery or oncology professional associations, but there are no similar evidence-based papers regarding the assessment of therapy response $(16,17)$. Except colonoscopy, the current imaging techniques used for the follow-up of neoadjuvant chemotherapy effects in colon cancer are represented by CT or PET-CT, whilst the recommended methods for assessing the effects of neoadjuvant chemoradiotherapy for rectal cancer are EUS, MRI and/or PET-CT. All these techniques do have several advantages but also different boundaries, including: costs, radiations risks, limited capacity to differentiate layers of the gut wall, missing small lesions under $1 \mathrm{~cm}$, false positive rate for the uninvolved lymph nodes, inter-observer variations, etc. (18).

Currently, CRC treatment involves surgical resection in early stages, associated or followed by chemotherapy and/or radiotherapy in avanced stages. Oncologic protocols comprise as first line chemotherapy 5 -fluorouracil (5-FU), irinotecan or their combination with folinic acid, being referred to as FOLFIRI therapy. Oxaliplatin, an analogue to cisplatin or carboplatin, in combination with 5-FU and folinic acid is known as FOLFOX therapy (19). Despite the improvement of neoadjuvant drugs, survival is less than 3 years among patients with metastatic colorectal cancer. Furthermore, the response to systemic therapy is not durable, in some cases lasting under 1 year (20). Along with the progress registered during the last decades in the domain of neoadjuvant therapy, an increased necessity was observed for the development of objective ways of accurately measuring treatment response. This might play a major role in distinguishing the patients who are responding properly to therapy from those requiring therapeutic adjustments.

Chemotherapy often has positive results initially but, at some point, malignant cells become refractory, with several mechanisms being blamed. These include $A B C$ transporter expression, aldehyde dehydrogenase (ALDH) activity, B-cell lymphoma-2 (BCL2) related chemoresistance, enhanced DNA damage response and activation of key signaling pathways (21). One theory states that tumors have a heterogeneous architecture of cancerous cells $(22,23)$. Out of this mass of tumour cells, only a subpopulation of CSCs is believed to survive chemotherapy due to heightened protective mechanism and slower division rate. Evidence suggests that this small sub-population of cells represents $0.1-10 \%$ of all tumor cells (24) out of which only a few have the potential to form tumors (25). When compared to normal stem cells, CSCs are considered not to possess any limitation regarding proliferation, but because it's a slow rate process it might be one of the factors connected to chemo-radiotheraphy resistance and also to tumor recurrence(26, 27). Cell cycle analysis has revealed that CSCs are slow cycling compared to the bulk of tumour cells, hence the need of identifying and assessing CSC (28), whilst the classic chemotherapy relies on the trademark that the cancer cells are proliferating with a high rate (29). Even the niches that CSCs reside in are considered itself a shelter from xenobiotics, radiation and ions. The detailed mechanisms of CSC radioresistance, chemoresistance, invasiveness and metastatic activity are already described amply in the literature (30-34).

In the present study, we have used a state-of-theart imaging technique, (CLE), for visualizing the expression of CD44 positive cells from fresh biopsies of normal and malignant colorectal tissue, in order to analyze and compare the results. To our knowledge, this is the first report on putative CSCs imaging obtained with a state-of-the-art technique such as CLE, utilized for describing the expression patterns of a fluorescently labeled antibody targeting a cancer stem cell marker (CD44) in fresh human CRC specimens. One previous CLE study involved animal models and Lgr5+ intestinal stem cell marker, described as a promising molecular marker for early diagnosis of colon adenomas. The combination of CLE and Lgr5 had the potential of predicting colonic tumors growth much earlier as compared to conventional colonoscopy (35).

We selected as molecular target a cell surface biomarker, labeling normal and tumor cancer stem cells in order to obtain a distinctive evaluation of the expression patterns. CD44 is a 80-95 kDa transmembrane glycoprotein, a member of hyaladherin family present on endothelial cells, leukocytes or mesenchymal cells surface (36). CD44 is activated by binding to hyaluronic acid (HA), process which adjusts stem cells homing. CSCs synthesize HA (the primary CD44 ligand) a reason for CD44 to be a common component of the stem cell niche. Also, HA attracts tumor-associated macrophages, together recruiting stromal cells in the CSCs niches. Stromal cells generate multiple growth factors that adjust stem cells activity and multiplication. (37-39) Hence, CD44 is thought to be responsible for cell to cell and cell-matrix interactions and is involved in celladhesion and the assembly of growth factors on the cell surface (40). The literature regarding the tumorigenicity of CD44 in CRC concurs, although the specific role of CD44 variants in the malignant cells is not well established yet. Thus, different experiments lead to incoherent results, sometimes even contradictory, one of the limitation that literature is recalling being that 
surface markers might not be reliable enough in differentiating CSC from normal stem cells or even other non-stem cells populations (41-47).

In our study, the CLE imaging showed through visual inspection obvious differences between the normal and tumor tissue architecture and CD44 positive CSCs patterns. Normal mucosal biopsy revealed a regular size and pattern of the crypts opening with equal distances between it. Luminal opening of the crypts appears as black holes. In tumor samples, the proper layout of normal mucosa structure was replaced by a disorganized architecture with unrecognizable clear structures as crypts. The literature is also describing the CLE aspects of colorectal malignant tissue as loss of crypts, irregular epithelial layer and blood vessels number, diameter, distribution, tortuosity, overall major disorders in cells architecture $(12,36,48)$. A higher proportion of putative CSCs in tumor tissue as compared to normal mucosa was also obvious, indicating that the absolute number of CD44 positive cells identified in real-time through CLE might represent a useful surrogate biomarker for the evaluation of prognosis and survival during chemoradiotherapy. These findings support even more the previous research studies, stating that endoscopy has advanced from predicting the histology of a tissue based on morphologic patterns to real-time histology through the visualization of cellular and subcellular details $(48,49)$.

The results obtained were not statistical relevant in all cases (probably due to the low number of patients included in the study groups or due to the limitation of a new staining and imaging technique, lacking the opportunity to compare and verify the preliminary results with other similar studies) and only a partial correlation with tumor staging and grading was observed. Nevertheless, several positive aspects regarding CLE should be taken into consideration. Using fresh tissue avoids the appearance of artifacts due to processing but the main advantage is represented by real time imaging of positive CD44 cells, performed within a short time after specimen harvest, which might considerably accelerate the diagnosis procedures.

In vivo CLE molecular imaging might not only facilitate the process of selecting the patients who could benefit from targeted therapies but also screen treatment response and patient evolution. Patients are more often diagnosed in already advanced stages. In T3/T4 rectal cancer, the established neoadjuvant radiochemotherapy is recommended, whilst the patients with locally advanced colon cancer also appear to benefit from the promising neoadjuvant chemotherapy (50). In both situations, drug resistance may influence the therapeutic response and concur to recurrent disease. Furthermore, recent studies propose various nanoparticles as a treatment option able to inhibit CSCs by targeting signaling pathways or specific biomarkers (51). In vivo follow-up of treatment results is therefore needed and CLE might be the imaging method to answer this need.

The findings of our proof of concept pilot study prove the utility of the CLE technique and establish a reliable background for additional research. The diminished timespan between sample collection and CLE imaging of the CD44 marked biopsies (a process settled to one hour in the present study), along with the usage of a predefined staining protocol for fresh tissue, makes the targeted molecular CLE method suitable within the clinical framework. Two other CSCs biomarkers (CD133 and CD166) were tested for evaluating their CLE expression but without relevant results. Improvements might be required regarding the CLE immunostaining technique, taking into consideration one of our previous histology study centered on CD133 and CD166 putative stem cells antibodies which registered consistent outcomes (52).

Once the advantages and applicability in clinical practice of immuno-CLE are settled, further studies should assess more than one CSCs biomarker, this representing one important limitation of the present study. It is already established by other studies involving standard immunohistochemical or molecular genetics techniques, that the combined use of biomarkers was effective in identifying CSCs and poor prognosis tumors (53-56). Identifying the optimum combination of biomarkers might be important in increasing the cancer detection rate, but also developing individualized therapy (8), thus representing viable research directions especially in the field of in vivo targeted CLE based on specific CSCs fluorescent antibodies.

\section{CONCLUSIONS}

This is the first study showing that CLE imaging can highlight the presence and expression patterns of the biomarker CD44. More importantly, our data show that the association of immuno-CLE with EUS might be a reliable pathway to be followed for both real-time diagnosis and staging, as well as tumor evaluation in CRC patients, especially during follow-up of advanced CRC patients undergoing neoadjuvant chemoradiotherapy protocols. Further studies involving a combination of CSC biomarkers evaluated through CLE, backed by immunohistochemistry and/or molecular biology validation, are required. 


\section{Acknowledgement}

There is no conflict-of-interest to declare. The study was reviewed and approved by the University of Medicine and Pharmacy of Craiova Institutional Review Board. All study participants provided informed written consent prior to study enrollment.

Technical appendix, statistical code and datasets are available from the corresponding author. Participants gave informed consent for data sharing.

\section{Support}

This work was supported by the grant ERC-like nr. 7 / 2012 "Real-time Evaluation of Treatment Effects in Advanced Colorectal Carcinoma (REACT)", project ID PNII-CT-ERC-2012-1, financed by the Executive Agency for Higher Education, Research, Development and Innovation Funding (CNCS-UEFISCDI), Romanian National Authority for Scientific Research, Ministry of National Education, Romania.

\section{REFERENCES}

1. International Agency for Research on Cancer. GLOBOCAN 2012: Estimated cancer incidence, mortality and prevalence worldwide in 2012. Lyon: IARC; 2013. Available from: http://globocan.iarc.fr/Pages/ fact_sheets_cancer.aspx.

2. Ferlaya J, Steliarova-Foucher E, Lortet-Tieulent J, Rossob S, Coeberghc JWW, Comber $\mathrm{H}$, et al. Cancer incidence and mortality patterns in Europe: Estimates for 40 countries in 2012. European Journal of Cancer 2013; 49: 1374-1403. doi: 10.1016/j.ejca.2012. 12.027. PMID: 23485231

3. United Nations. World Population Ageing: 1950-2050. Department of Economic and Social Affairs/Population Division. New York: United Nations; 2002. Available from: http://www.un.org/esa/population/publications/wpp2002/WPP2002-HIGHLIGHTSrev1.PDF

4. McKeown E, Nelson DW, Johnson EK, Maykel JA, Stojadinovic A, Nissan A, et al. Current Approaches and Challenges for Monitoring Treatment Response in Colon and Rectal Cancer. J Cancer 2014; 5(1): 31-43. doi:10.7150/jca.7987. PMID:24396496

5. Yu Y, Kanwar SS, Patel BB, Nautiyal J, Sarkar FH, Majumdar AP. Elimination of Colon Cancer Stem-Like Cells by the Combination of Curcumin and FOLFOX. Translational Oncology. 2009;2(4):321-328.

6. Huang R, Wang G, Song Y, Tang Q, You Q, Liu Z, et al. Colorectal cancer stem cell and chemoresistant colorectal cancer cell phenotypes and increased sensitivity to Notch pathway inhibitor. Mol Med Rep. 2015;12(2): 2417-24. doi: 10.3892/mmr.2015.3694. Epub 2015 Apr 28.

7. Sprenger T, Conradi LC, Beissbarth T, Ermert H, Homayounfar K, Middel P, et al. Enrichment of CD133-expressing cells in rectal cancers treated with preoperative radiochemotherapy is an independent marker for metastasis and survival. Cancer. 2013;119(1):26-35. doi: 10.1002/cncr.27703. Epub 2012 Jun 26.

8. Cherciu I, Bărbălan A, Pirici D, Mărgăritescu C, Săftoiu A. Stem cells, colorectal cancer and cancer stem cell markers correlations. Curr Health Sci J. 2014;40(3):153-61. doi: 10.12865/CHSJ.40.03.01. Epub 2014 Aug 4.

9. Horst D1, KriegI L, Engel J, Kirchner T, Jung A. Prognostic significance of the cancer stem cell markers CD133, CD44, and CD166 in colorectal cancer. Cancer Invest. 2009; 27(8):844-50. doi: 10.1080/ 07357900902744502.

10. Malmstrøm ML, Karstensen JG, Saftoiu A, Riis LB, Gögenur I,
Vilmann P. Confocal laser endomicroscopy is a new endoscopic technique for diagnosing colorectal neoplasia and inflammatory bowel disease. Ugeskr Laeger. 2014;176(40). pii: V05130311. Danish

11. Goetz M. Confocal Laser Endomicroscopy: Applications in Clinical and Translational Science - A Comprehensive Review. ISRN Pathology. 2012, Article ID 387145, 13 pages, 2012. doi:10.5402/2012/387145.

12. Kiesslich R, Burg J, Vieth M, Gnaendiger J, Enders M, Delaney P, et al. Confocal laser endoscopy for diagnosing intraepithelial neoplasias and colorectal cancer in vivo. Gastroenterology. 2004;127:706-713.

13. Gheonea DI, Saftoiu A, Ciurea T, Popescu C, Georgescu CV, Malos A. Confocal Laser Endomicroscopy of the Colon. J Gastrointestin Liv Dis. 2010;19:207-11.

14. Baeten J, Suresh A, Johnson A, Patel K, Kuriakose M, Flynn A, et al. Molecular imaging of oral premalignant and malignant lesions using fluorescently labeled lectins. Transl Oncol. 2014;7(2):213-20. doi: 10.1016/j.tranon.2014.02.006. Epub 2014 Mar 4.

15. Olivo M, Bhuvaneswari R, Keogh I. Advances in Bio-Optical Imaging for the Diagnosis of Early Oral Cancer. Pharmaceutics. 2011;3(3):354378. doi:10.3390/pharmaceutics3030354.

16. Valentini V, Glimelius B, Haustermans K, Nordlinger B, van de Velde CJ, Balmana J, et al. ESMO Consensus Guidelines for management of patients with colon and rectal cancer. A personalized approach to clinical decision making. Ann Oncol. 2012 Oct;23(10):2479-516.

17. American Gastroenterology Association. AGA institute guidelines for colonoscopy surveillance after cancer resection: clinical decision tool. Gastroenterology. 2014;146(5):1413-4.

18. McKeown E, Nelson DW, Johnson EK, Maykel JA, Stojadinovic A, Nissan A, et al. Current approaches and challenges for monitoring Treatment Response in colon and rectal cancer. J Cancer 2014; 5(1): 31-43. doi:10.7150/jca.7987.

19. Kelly H, Goldberg RM. Systemic therapy for metastatic colorectal cancer: Current options, current evidence. J Clin Oncol. 2005;23(20): 4553-60.

20. Rui Wang, Fan Fan, Delphine Boulbes, Rajat Bhattacharya, Xiang-Cang Ye, Ling Xia, Lee Ellis. ADAM17 mediation of cancer stem cell-ness and chemo-resistance in colorectal cancer. (abstract). In: Proceedings of the 106th Annual Meeting of the American Association for Cancer Research; 2015 Apr 18-22; Philadelphia, PA. Philadelphia (PA): AACR; Cancer Res 2015;75(15 Suppl):Abstract nr 2337. doi:10.1158/15387445.AM2015-2337

21. Siddik ZH. Cisplatin: mode of cytotoxic action and molecular basis of resistance. Oncogene. 2003;22(47):7265-79.

22. Hanahan D, Weinberg RA. Hallmarks of cancer: the next generation. Cell. 2011;144(5):646-74. doi: 10.1016/j.cell.2011.02.013.

23. Dick JE. Stem cell concepts renew cancer research. Blood. 2008; 112(13):4793-807. doi: 10.1182/blood-2008-08-077941.

24. Deonarain MP, Kousparou CA, Epenetos AA. Antibodies targeting cancer stem cells: a new paradigm in immunotherapy? MAbs. 2009; 1(1):12-25

25. Nguyen LV, Vanner R, Dirks P, Eaves CJ. Cancer stem cells: an evolving concept. Nat Rev Cancer. 2012;12(2):133-43.

26. Moore N, Lyle S. Quiescent, slow-cycling stem cell populations in cancer: a review of the evidence and discussion of significance. J Oncol. 2011;2011. pii: 396076. doi: 10.1155/2011/396076. Epub 2010 Sep 29.

27. Pannuti A, Foreman K, Rizzo P, Osipo C, Golde T, Osborne B, et al. Targeting notch to target cancer stem cells. Clin Cancer Res. 2010;16(12):3141-52.

28. Yan J, Tang D. Prostate cancer stem-like cells proliferate slowly and resist etoposide-induced cytotoxicity via enhancing DNA damage response. Exp Cell Res. 2014;328(1):132-42. doi: 10.1016/j.yexcr. 2014.08.016. Epub 2014 Aug 20.

29. Hanahan D, Weinberg RA. The hallmarks of cancer. Cell. 2000;100(1): 57-70.

30. Baumann M, Krause M, Hill R. Exploring the role of cancer stem cells in radioresistance. Nat Rev Cancer. 2008;8(7):545-54. doi: 10.1038/nrc2419. Epub 2008 May 30.

31. Moncharmont C, Levy A, Gilormini M, Bertrand G, Chargari C, Alphonse $\mathrm{G}$, et al. Targeting a cornerstone of radiation resistance: cancer stem cell. Cancer Lett. 2012;322(2):139-47. doi: 10.1016/ j.canlet.2012.03.024. Epub 2012 Mar 27. 
32. Charafe-Jauffret E, Ginestier C, lovino F, Wicinski J, Cervera N, Finetti $P$, et al. Breast cancer cell lines contain functional cancer stem cells with metastatic capacity and a distinct molecular signature. Cancer Res. 2009; 69(4):1302-13. doi: 10.1158/0008-5472.CAN-08-2741. Epub 2009 Feb 3.

33. Hermann PC, Huber SL, Herrler T, Aicher A, Ellwart JW, Guba M, et al. Distinct populations of cancer stem cells determine tumor growth and metastatic activity in human pancreatic cancer. Cell Stem Cell. 2007; 1(3):313-23. doi: 10.1016/.stem.2007.06.002.

34. Liao J, Qian F, Tchabo N, Mhawech-Fauceglia P, Beck A, Qian Z, et al. Ovarian cancer spheroid cells with stem cell-like properties contribute to tumor generation, metastasis and chemotherapy resistance through hypoxia-resistant metabolism. PLoS One. 2014;9(1):e84941. doi: 10.1371/journal.pone.0084941. eCollection 2014.

35. Choi JW, Kim JK, Choi M, Kim YR, Yun SH. In vivo imaging of Lgr5positive cell populations using confocal laser endomicroscopy during early colon tumorigenesis. Endoscopy. 2014;46(12):1110-6. doi: 10.1055/s-0034-1377631. Epub 2014 Sep 12.

36. Monoclonal anti-CD44-APC antibody Produced in mouse clone MEM85, purified immunoglobulin, buffered aqueous solution. Available at http://www.sigmaaldrich.com/catalog/product/sigma/sab4700180?la $\mathrm{ng}=$ =n\&region=R0 Accessed: 10 November 2015

37. Basakran NS. CD44 as a potential diagnostic tumor marker. Saudi Med J. 2015 Mar:36(3):273-9. doi: 10.15537/smi.2015.3.9622.

38. Williams K, Motiani K, Giridhar PV, Kasper S. CD44 integrates signaling in normal stem cell, cancer stem cell and (pre)metastatic niches. Exp Biol Med (Maywood). 2013;238(3):324-38. doi: 10.1177/ 1535370213480714

39. Williams K, Motiani K, Giridhar PV, Kasper S. CD44 integrates signaling in normal stem cell, cancer stem cell and (pre)metastatic niches. Exp Biol Med (Maywood). 2013;238(3):324-38. doi: 10.1177/ 1535370213480714

40. Sahlberg SH, Spiegelberg D, Glimelius B, Stenerlöw B, Nestor M Evaluation of Cancer Stem Cell Markers CD133, CD44, CD24: Association with AKT Isoforms and Radiation Resistance in Colon Cancer Cells. Yeudall A, ed. PLoS One. 2014;9(4):e94621. doi: 10.1371/journal.pone.0094621. eCollection 2014.

41. Zwick E, Bange J, Ullirich A. Receptor tyrosine kinase signalling as a target for cancer intervention strategies. Endocr Relat Cancer. 2001; 8(3):161-73

42. Haruyama K, Matsumura Y, Moriya Y, Kakizoe T, Ochiai A, Kawaguchi MS. Clinicopathological significance of the expression of CD44v2 in colorectal cancer. Anticancer Res. 1999;19(5C):4421-8.

43. Barbour AP, Reeder JA, Walsh MD, Fawcett J, Antalis TM, Gotley DC Expression of the CD44v2-10 isoform confers a metastatic phenotype: importance of the heparan sulfate attachment site CD44v3. Cancer Res. 2003 Feb 15;63(4):887-92.

44. Ropponen KM, Eskelinen MJ, Lipponen PK, Alhava E, Kosma VM. Expression of CD44 and variant proteins in human colorectal cancer and its relevance for prognosis. Scand J Gastroenterol. 1998; 33(3): 301-9.

45. Yamada Y, Itano N, Narimatsu H, Kudo T, Hirohashi S, Ochiai A, et al. CD44 variant exon 6 expressions in colon cancer assessed by quantitative analysis using real time reverse transcriptase-polymerase chain reaction. Oncol Rep. 2003;10(6):1919-24.

46. Dong WG, Sun XM, Yu BP, Luo HS, Yu JP. Role of VEGF and CD44v6 in differentiating benign from malignant ascites. World $\mathrm{J}$ Gastroenterol. 2003:9(11):2596-600.

47. Morrin M, Delaney PV. CD44v6 is not relevant in colorectal tumour progression. Int J Colorectal Dis. 2002;17(1):30-6.

48. Kiesslich R, Peter R. Galle, Markus F. Neurath. Atlas of Endomicroscopy. Springer Medizin Verlag Heidelberg, 2007.

49. Goetz M. Real time histology in colonoscopy, Gastroenterol Clin North Am. 2013;42(3):567-75. doi: 10.1016/j.gtc.2013.05.004

50. Foxtrot Collaborative Group. Feasibility of preoperative chemotherapy for locally advanced, operable colon cancer: the pilot phase of a randomised controlled trial. Lancet Oncol. 2012;13(11):1152-60. doi: 10.1016/S1470-2045(12)70348-0 PMID:23017669

51. Hong IS, Jang GB, Lee HY, Nam JS. Targeting cancer stem cells by using the nanoparticles. Int J Nanomedicine. 2015;10(Spec Iss):25160. doi: 10.2147/JJN.S88310. eCollection 2015.

52. Mărgaritescu C, Pirici D, Cherciu I, Bărbălan A, Cârtână T, Săftoiu A.CD133/CD166/Ki-67 triple immunofluorescence assessment for putative cancer stem cells in colon carcinoma. J Gastrointestin Liver Dis. 2014;23(2):161-70.

53. Chen KL, Pan F, Jiang H, Chen JF, Pei L, Xie FW, et al. Highly enriched CD133(+)CD44(+) stem-like cells with CD133(+)CD44(high) metastatic subset in HCT116 colon cancer cells. Clin Exp Metastasis. 2011;28(8):751-63. doi: 10.1007/s10585-011-9407-7.

54. Galizia G, Gemei M, Del Vecchio L, Zamboli A, Di Noto R, Mirabelli P, et al. Combined CD133/CD44 expression as a prognostic indicator of disease-free survival in patients with colorectal cancer. Arch Surg. 2012;147(1):18-24. doi: 10.1001/archsurg.2011.795.

55. Horst D, Kriegl L, Engel J, Kirchner T, Jung A. Prognostic significance of the cancer stem cell markers CD133, CD44, and CD166 in colorectal cancer. Cancer Invest. 2009;27(8):844-50. doi: 10.1080/ 07357900902744502

56. Huang EH, Wicha MS. Colon cancer stem cells: implications for prevention and therapy. Trends Mol Med. 2008;14(11):503-9. doi: 10.1016/j.molmed.2008.09.005. Epub 2008 Oct 17. 